\author{
Aedes Aegypti: \\ Insecticides, Mechanisms of Action and Resistance
}

\author{
Ima Aparecida Braga \\ Programa Nacional de Controle da Dengue, Diretoria Técnica de Gestão, Secretaria de Vigilância em Saúde, Ministério da Saúde, \\ Brasília-DF, Brasil

\section{Denise Valle} \\ Laboratório de Fisiologia e Controle de Artrópodes Vetores, Instituto Oswaldo Cruz, Fundação Instituto Oswaldo Cruz, \\ Rio de Janeiro-RJ, Brasil
}

\title{
Resumo
}

No Brasil, o Aedes aegypti é responsável pela transmissão de dengue e o Aedes albopictus, potencial vetor, está se disseminando no país. 0 uso de inseticidas químicos ainda é o principal componente de controle do vetor. A ação das principais classes dos compostos tradicionalmente usados em Saúde Pública é descrita, assim como os mecanismos de resistência selecionados pelas populações do vetor. Produtos alternativos, com potencial de utilização no controle do A. aegypti, incluindo o biolarvicida Bti e alguns reguladores do desenvolvimento de insetos, também são discutidos. Pretende-se contribuir com o uso racional de inseticidas, considerando os diferentes componentes do controle integrado.

Palavras-chave: Aedes aegypti; Aedes albopictus; inseticida; resistência.

\section{Summary}

In Brazil, dengue is transmitted by Aedes aegypti. Aedes albopictus, a potential dengue vector, is spreading all over the country. The use of chemical insecticides is yet the main vector control component. The action of the main classes of compounds traditionally employed in Public Health is described, as well as the resistance mechanisms selected by vector populations. Alternative products, with potential to be used in the control of A. aegypti, including the biolarvicide Bti and some insect growth regulators, are also discussed. The authors aim at contributing with the rational insecticide use, taking into account the different components of the integrated control.

Key words: Aedes aegypti; Aedes albopictus; insecticide; resistance.

\footnotetext{
* Este trabalho contou com o apoio da Secretaria de Vigilância em Saúde e da Fundação Oswaldo Cruz do Ministério da Saúde, do Conselho Nacional de Desenvolvimento Científico e Tecnológico do Ministério da Ciência e Tecnologia, e da Fundação Carlos Chagas Filho de Amparo à Pesquisa do Estado do Rio de Janeiro.
}

Endereço para correspondência:

Ministério da Saúde, Secretaria de Vigilância em Saúde, Diretoria Técnica de Gestão, Programa Nacional de Controle da Dengue, Esplanada dos Ministérios, Bloco G, Edifício-sede, $1^{\circ}$ Andar, Brasília-DF. CEP: 70058-900

E-mail:ima.braga@saude.gov.br; dvalle@ioc.fiocruz.br 


\section{Introdução}

A dengue é uma doença transmitida por mosquitos do gênero Aedes, sendo incriminadas várias espécies do subgênero Stegomyia (Aedes aegypti, Aedes albopictus e Aedes polynesiensis), nas quais o vírus foi encontrado in natura. ${ }^{1,2}$ Experimentos em laboratório também mostraram a susceptibilidade de outras espécies de Aedes ao vírus da dengue. ${ }^{2} 0$ mais importante vetor de dengue, entretanto, é oAedes aegypti. OAedes albopictus é um vetor de importância secundária na Ásia; ${ }^{3}$ contudo, em algumas áreas da Indonésia, têm ocorrido surtos com frequiência, nas partes rurais do país, onde oAe. albopictus é a espécie predominante. ${ }^{4}$ Ademais, estudos sobre a transmissão de dengue em vilas da Tailândia indicaram importante papel do $A e$. albopictus na transmissão dessa doença. ${ }^{5,6}$ Nas Américas, o Ae. albopictus ainda não foi incriminado de maneira consistente como vetor de dengue, embora alguns estudos tenham encontrado mosquitos naturalmente infectados. ${ }^{7,8}$

Tanto o Ae. aegypti quanto o Ae. albopictus são importantes vetores de arbovírus para o homem. Ambas são espécies exóticas que chegaram ao continente americano após desenvolverem, em seus ambientes primários, grau significante de sinantropia. Geralmente, a ocorrência de epidemias de dengue está diretamente relacionada com a presença e a densidade de seus vetores. ${ }^{2,9}$

\section{Aedes aegypti}

OAedes aegypti (Diptera: Culicidae) é um mosquito originário da África, onde existem populações selvagens e domésticas. Originalmente descrito no Egito, 0 que lhe conferiu seu nome específico (Aedes aegypti), ele tem acompanhado o homem em sua permanente migração. ${ }^{10,11}$

A espécie $A e$. aegypti tem distribuição mundial. Encontra-se, em geral, entre as latitudes $35^{\circ}$ Norte e $35^{\circ}$ Sul, que correspondem à isoterma de inverno de $10^{\circ} \mathrm{C}$. A distribuição desse mosquito também é restrita à altitude. Embora a espécie não seja normalmente encontrada em zonas acima de 1.000 metros de altitude, sua presença já foi detectada a alturas de mais de 2.000 metros, na Índia e na Colômbia. ${ }^{12}$

É um mosquito adaptado ao ambiente urbano e utiliza os recipientes mais freqüentes no domicílio ou peridomicílio - tanques de armazenamento de água e vasilhames temporários, dentro e fora das casas, como potes, barris, pneumáticos usados, latas, garrafas e vasos de plantas - para o desenvolvimento de sua fase larvária. ${ }^{10,11}$ As larvas também podem ser encontradas em calhas de telhado, axilas de folhas, bambus cortados. Essa espécie é antropofílica e tem hábitos diurnos, alimentando-se e depositando seus ovos, preferencialmente, ao amanhecer e no período vespertino próximo ao crepúsculo. ${ }^{10}$

\section{Geralmente, a ocorrência de epidemias de dengue está diretamente relacionada com a presença e a densidade de seus vetores, como o Aedes aegypti 0 Aedes albopictus.}

O Ae. aegypti foi reconhecido como transmissor da febre amarela em 1881, por Carlos J. Finlay. ${ }^{13,14} \mathrm{Em}$ 1906, Brancroft publicou as primeiras evidências de que o mosquito também era 0 vetor de dengue, fato posteriormente confirmado por Agramonte, em 1906, e por Simmons, em 1931..$^{5-17}$

Provavelmente, esse vetor foi introduzido nas Américas a bordo de barcos vindos da Europa, que cruzavam o Atlântico durante as primeiras explorações e colonizações européias ao Novo Mundo. ${ }^{14}$ Os primeiros registros de sua identificação em terras do Brasil foram em 1898, por Lutz, e em 1899, por Ribas. ${ }^{18}$

Atualmente, 0 vetor é encontrado em uma larga faixa do continente americano, que se estende do Uruguai até o sul dos Estados Unidos da América (EUA), com a ocorrência de surtos importantes de dengue em vários países, como Venezuela, Cuba, Brasil e, recentemente, Paraguai. ${ }^{19}$ No Brasil, o Ae aegypti está presente nos 26 Estados e no Distrito Federal. ${ }^{20}$ A distribuição do mosquito no país em 2006 pode ser observada na Figura 1.

Aedes aegypti continua sendo o único vetor incriminado na transmissão de dengue no Brasil e estudos recentes confirmam sua capacidade de se infectar com os vírus da dengue e da febre amarela. Este trabalho também verificou que os mosquitos coletados em áreas endêmicas e de transição da febre amarela silvestre tinham alta susceptibilidade ao vírus amarílico. ${ }^{21}$ 


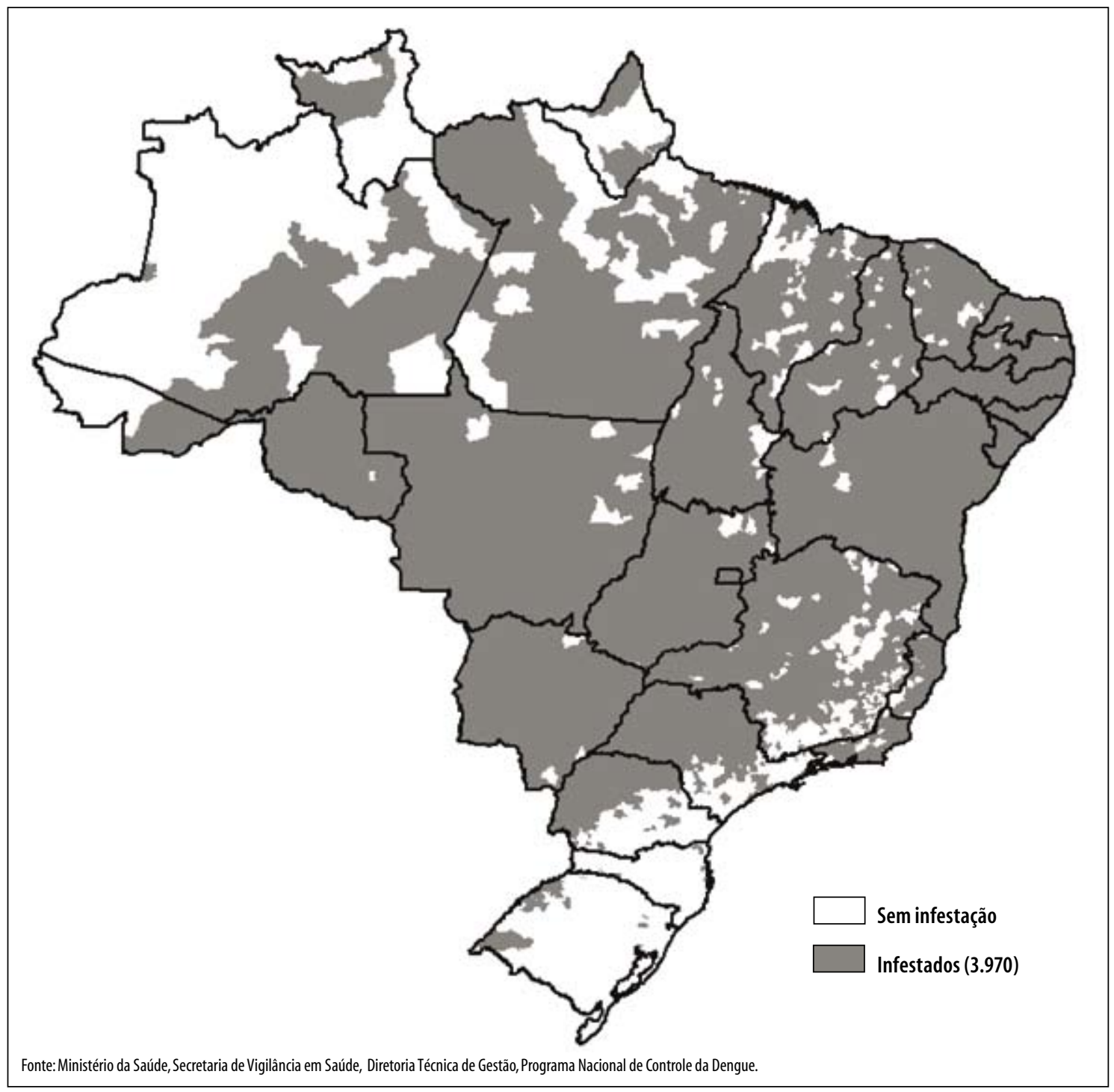

Figura 1 - Distribuição do Aedes aegypti. Brasil, 2006

\section{Aedes albopictus}

Embora o Ae. albopictus também seja encontrado em vasilhames temporários, essa espécie prefere 0 habitat natural da floresta, como buracos em árvores, axilas de folhas, internódios de bambus e cascas de coco. Cria-se, mais frequientemente, fora das casas, em jardins; e com menor frequiência dentro delas, em vasilhames artificiais.

Recentemente, a espécie invadiu o oeste da África e as Américas do Sul e do Norte, onde pode vir a se tornar importante na transmissão de dengue e outras doenças virais. Provavelmente, o intenso comércio de pneumáticos usados tem sido o responsável pela dispersão desse mosquito para novas áreas, nas últimas duas décadas. ${ }^{22}$

0 primeiro registro do Ae albopictus no Brasil data de 1986, no Estado do Rio de Janeiro. ${ }^{23}$ Estudos realizados naquele mesmo ano, pela extinta Superintendência de Campanhas de Saúde Pública do Ministério da Saúde (Sucam), verificaram a presença da espécie nos Estados de Minas Gerais e de São Paulo; e no ano seguinte, no Estado do Espírito Santo. Assim, em apenas um ano, o Ae. albopictus já se encontrava instalado em todos os Estados da Região Sudeste. ${ }^{24}$ 
Desde sua introdução no país, é crescente e acelerada a expansão do Ae. albopictus e apenas sete Estados ainda não relataram infestação por essa espécie: Amapá, Roraima, Acre e Tocantins (Região Norte); e Piaú, Ceará e Sergipe (Região Nordeste). Até o ano de 2002, os Estados do Pará e de Alagoas haviam registrado sua ocorrência em apenas um Município - Medicilândia e Maceió, respectivamente. ${ }^{25}$

OAedes albopictus é um vetor potencial de dengue epidêmica. Ainda é obscuro o efeito que a presença dessa espécie pode provocar na dinâmica de transmissão da doença nas Américas. Acredita-se que também possa afetar o potencial de transmissão da febre amarela no Brasil, atravessando o nicho ecológico entre a selva e os ciclos de transmissão urbanos. Atualmente, em razão de seu potencial como vetor, os Centers for Diseases Control and Prevention (CDC) dos EUA mantêm um banco de dados da distribuição do Ae. albopictus naquele país, com ênfase particular no monitoramento de sua expansão para áreas nas quais o vírus La Crosse e 0 vírus da encefalite equiina oriental são enzoóticos. ${ }^{26}$

Em 1995, esse vetor foi encontrado pela primeira vez na América, naturalmente infectado com o vírus da dengue, durante um surto da doença ocorrido no México. Os vírus DEN-1 e DEN-3 foram detectados em machos adultos, indicando transmissão transovariana de dengue naquela região do continente. ${ }^{8}$ Embora não se tenha registro de transmissão de dengue no Brasil por Ae. albopictus, não se pode deixar de estar vigilante quanto a sua potencial importância como vetor, visto que ele tem se disseminado nos ambientes rural, semi-rural e, inclusive, urbano. Em testes de laboratório, a primeira população de Ae. albopictus detectada no Brasil demonstrou capacidade de transmitir dengue, febre amarela e vírus de encefalite equiina venezuelana. ${ }^{27}$

Análise comparativa da susceptibilidade, em condições experimentais, aos vírus DEN-2 e da febre amarela, de mosquitos coletados em várias localidades do Brasil e dos EUA, detectou, nos dois casos, maior heterogeneidade na susceptibilidade das populações brasileiras. Com relação à transmissão transovariana, no Brasil, há registro de apenas uma infecção natural por vírus da dengue (DEN-1) em larvas de $\boldsymbol{A} \boldsymbol{e}$. albopictus coletadas no Município de Campos Altos, Estado de Minas Gerais. ${ }^{7,28}$

\section{Controle de vetores}

Práticas para controle de insetos são muito antigas. Há registro de seu uso na China há mais de 2.000 anos. Basicamente, eram práticas de controle biológico direcionadas ao enfrentamento das pragas agrícolas.

No final do século XIX, descobriu-se que certas espécies de insetos e outros artrópodos eram responsáveis pela transmissão de algumas das mais importantes doenças. Vacinas ou medicamentos efetivos contra a maioria delas ainda não estavam disponíveis e o controle da transmissão era, todavia, fortemente centralizado no combate ao vetor. Os primeiros programas de controle eram baseados em medidas físicas e na aplicação de óleo ou de verde de Paris nos criadouros. ${ }^{29}$ Atualmente, muitas doenças contam com vacinas eficazes, caso da febre amarela, ou com medicamentos geralmente eficientes, caso da malária. Todavia, o controle do vetor ainda é imprescindível para prevenir diversas doenças - entre as quais a dengue é o melhor exemplo -, parte integrante de muitos programas de saúde, como os dirigidos à prevenção $\mathrm{e}$ controle da malária e das leishmanioses.

O papel do controle de vetores em Saúde Pública é prevenir a infecção mediante o bloqueio ou redução da transmissão, sendo seus principais objetivos:

I) Manejar os problemas existentes, como surtos, epidemias, alta mortalidade e alta morbidade.

II) Prevenir epidemias ou a re-introdução de doenças.

III) Reduzir os fatores de risco ambiental da transmissão.

Para que esses três objetivos sejam alcançados, é necessário contar com informações sobre o hospedeiro humano, a doença, o vetor e o ambiente; e dispor dos recursos necessários para aplicação oportuna. ${ }^{30}$

0 controle efetivo dos vetores não pode depender de um só método. Ao contrário, ele deve dispor de várias alternativas, adequadas à realidade local, que permitam sua execução de forma integrada e seletiva. $^{12,30}$

O controle (ou manejo) integrado trata do planejamento unificado de controle, de acordo com as condições ambientais e a dinâmica populacional do vetor. São selecionados os métodos de controle apropriados e as populações do vetor são mantidas em níveis que não causam dano à saúde. ${ }^{12}$ 
0 controle seletivo do vetor, definido pela Organização Mundial da Saúde (OMS), pode ser considerado uma operacionalização do controle integrado. Ele inclui a seleção das metodologias mais efetivas a serem utilizadas, com base na realidade local, e compreende três fases: a) definição de local; b) levantamento das informações necessárias; e c) decisão sobre o momento e a forma de sua implementação. ${ }^{30-33}$

Os componentes do controle integrado de vetores incluem vigilância, redução da fonte (ou manejo ambiental), controle biológico, controle químico com uso de inseticidas e repelentes, armadilhas e manejo da resistência a inseticidas. ${ }^{34}$

0 manejo ambiental lança mão de medidas para eliminar o vetor ou seus focos, ou, ainda, para impedir o contato homem-vetor, como a eliminação de criadouros, a drenagem e a instalação de telas em portas e janelas.

0 controle biológico de mosquitos inclui o uso de vários predadores, invertebrados aquáticos (como Toxorhynchites ou copépodos) ou peixes (Gambusia $s p$. e outros) que comem larvas e pupas. Entre as medidas de controle biológico, também se encontram o uso de patógenos, como o fungo Lagenedium giganteum, e de parasitas, como os nemátodeos (Romanomermis culicivorax e $R$. iyengari).$^{34}$ Vários agentes de controle biológico apresentaram um bom potencial para suprimir populações de mosquitos, como o peixe predador Gambusia affinis, ${ }^{35}$ as bactérias patógenas Bacillus thuringiensis israelensis (Bti) ${ }^{36}$ e Bacillus sphaericus (Bs) ${ }^{37,38}$ e o fungo patógeno Metharizium anisopliae. ${ }^{39}$

\section{Inseticidas químicos}

O controle químico, com inseticidas de origem orgânica ou inorgânica, é uma das metodologias mais adotadas como parte do manejo sustentável e integrado para 0 controle de vetores em Saúde Pública. ${ }^{34} 0$ desenvolvimento de inseticidas que permanecem ativos por períodos longos foi um dos mais importantes avanços no controle de insetos acontecidos no século XX. 0 primeiro inseticida de efeito prolongado, ou propriedade residual, foi o dicloro-difenil-tricloroetano (DDT), um organoclorado desenvolvido durante a Segunda Guerra Mundial, que, quando aplicado em paredes e tetos de casas, permanecia ativo contra os insetos por vários meses. ${ }^{29}$
Os outros compostos orgânicos pertencem, principalmente, aos grupos dos organofosforados, carbamatos ou piretróides. Todos esses grupos atuam sobre 0 sistema nervoso central dos insetos e têm sido usados nos programas de controle de doenças transmitidas por vetores. ${ }^{40-42}$

\section{Organoclorados}

Os organoclorados são inseticidas que contêm carbono, hidrogênio e cloro. São classificados em quatro grupos: difenil-alifáticos; hexaclorociclohexanos; ciclodienos; e policloroterpenos. ${ }^{43}$

0 grupo de organoclorados difenil-alifáticos é o mais antigo. Ele inclui o DDT, provavelmente a substância química mais notória do século passado. Em 1948, o entomologista suíço Paul Muller foi premiado com o Prêmio Nobel de Medicina pela descoberta da utilidade do DDT no controle dos vetores de malária, febre amarela e muitas outras doenças. ${ }^{43}$ Embora 0 modo de ação do inseticida nunca tenha sido claramente estabelecido, sabe-se que ele atua no canal de sódio, provavelmente mantendo-o aberto e destruindo o equilíbrio de íons sódio e potássio dos axônios, impedindo, assim, a transmissão normal de impulsos nervosos em insetos e mamíferos. Seu efeito é inversamente proporcional à temperatura: quanto mais baixa a temperatura, mais tóxico é o DDT para os insetos. ${ }^{43}$

\section{0 controle do vetor ainda é imprescindível para prevenir e controlar doenças como a dengue, a malária e as leishmanioses.}

0 benzenohexacloro (BHC), do grupo dos hexaclorociclohexanos $(\mathrm{HCH})$, também comercializado com 0 nome de lindano ${ }^{43}$ tem ação semelhante à do DDT.

Os inseticidas ciclodienos, como clordano, aldrin e dieldrin, surgiram após a Segunda Guerra Mundial. A maioria deles é persistente e estável no solo; e relativamente estável, quando exposta à luz solar ou ultravioleta. Por essas características, foram usados principalmente como inseticidas para o controle de térmitas e outros insetos cujas fases larvares alimentam-se nas raízes de plantas. ${ }^{43}$ Os ciclodienos inibem o receptor de ácido gama-aminobutírico (GABA), que, após ligação do neurotransmissor, aumenta a 
permeabilidade dos neurônios aos íons cloreto. Os ciclodienos impedem a entrada dos íons cloreto nos neurônios, antagonizando os efeitos do receptor de GABA. Ao contrário do DDT e dos HCH, os ciclodienos apresentam uma correlação positiva entre temperatura e toxicidade.

Apenas dois policloroterpenos, cujo modo de ação é equivalente ao dos ciclodienos, foram desenvolvidos: 0 toxafeno, (em 1947) e o estrobane (em 1951) vieram a ser usados mais intensamente na agricultura. ${ }^{43}$

Os organoclorados, embora tenham sido largamente adotados pelos programas de controle de malária, tiveram seu uso descontinuado e chegaram, inclusive, a ser proibidos em vários países devido a sua persistência no ambiente e ao acúmulo em tecidos do organismo de animais e de humanos. ${ }^{42,44-46}$ Essas proibições e restrições referiram-se ao uso agrícola do DDT, embora o inseticida ainda permaneça, até os dias de hoje, indicado pela OMS para uso no controle de vetores. ${ }^{31,47} \mathrm{O}$ uso descontinuado do DDT em Saúde Pública deveu-se, principalmente, a pressões internacionais e nacionais contínuas, aliadas a táticas de comercialização agressivas de produtores de outros inseticidas, estes mais caros. ${ }^{48}$

A publicação de trabalhos relacionados ao DDT relatando a presença da substância no leite materno e sua associação com a ocorrência de câncer em humanos ${ }^{49-51}$ fez com que a OMS encomendasse a um grupo de especialistas, reunidos em comitê, a revisão completa da literatura sobre o inseticida. As conclusões desse comitê, apresentadas em 1993, foram no sentido de que, “... em decorrência da falta de evidência suficiente e convincente acerca dos efeitos adversos da exposição ao DDT pelas aplicações residuais para controle de vetores, não existe justificativa toxicológica ou epidemiológica para alterar a política de uso do produto no controle da malária e leishmaniose." 310 documento, entretanto, sugere que os países ainda usuários do DDT façam a substituição por outros inseticidas, deixando de considerá-lo como única possibilidade.

Atualmente, vários pesquisadores que trabalham no controle da malária advogam o uso do DDT em países com alta transmissão e que não dispõem de condições monetárias de adquirir outro produto com efeito similar. ${ }^{48,52}$ Durante a reunião do Comitê Inter-governamental em Contaminantes Orgânicos Persistentes (Cicop) na África do Sul, no final de 2000, cuja finalidade era estabelecer um acordo internacional que permitisse implementar ações relativas aos compostos orgânicos persistentes (COP), resolveu-se, dada sua importância para a Saúde Pública, pela não-inclusão do DDT na lista de COP aos quais haviam sido impostas restrições.

Essas recomendações devem perdurar até que se estabeleça uma política de substituição do inseticida nos países usuários. Para tanto, foi discutida a necessidade da definição de prazos e apoio financeiro, visto que, geralmente, os países que continuam a usar o DDT não possuem recursos para arcar com os custos de sua substituição.

\section{Organofosforados}

0 termo genérico 'organofosforado' (OP), atualmente usado, inclui todos os inseticidas que contêm fósforo. Esses inseticidas foram descobertos posteriormente aos organoclorados..$^{53}$ No grupo dos organofosforados, classificamos os inseticidas em três subgrupos: os alifáticos (malation, vapona, vidrin, etc.); os derivados de fenil (etil e metil paration, fenitrotion, etc.); e os heterocíclicos (clorpirifos, clorpirifos-metil, etc.). São amplamente utilizados em Saúde Pública por apresentarem muitas vantagens sobre os organoclorados, como serem biodegradáveis e não se acumularem nos tecidos. Apresentam, porém, como principal desvantagem, a instabilidade química, o que torna obrigatória a renovação periódica de sua aplicação. Além disso, são mais tóxicos para os vertebrados que os organoclorados, mesmo em doses relativamente baixas. ${ }^{42,43}$

\section{0 uso continuado de inseticidas, tanto na agricultura e pecuária como na área da Saúde Pública, tem provocado 0 aparecimento de populações resistentes e ocasionado problemas para 0 controle de vetores.}

0 organofosforado temephos, registrado nos EUA em 1965, para utilização em agricultura e controle de mosquitos, é o único larvicida desse grupo com uso generalizado no controle de larvas de mosquitos, recomendado pela OMS para uso em água potável. ${ }^{47}$

Os organofosforados atuam inibindo a Acetilcolinesterase (AChE), importante enzima do sistema nervoso 
central. Essa enzima é fosforilada pelo inseticida, ficando irreversivelmente inativada. A inibição de AChE resulta no acúmulo de acetilcolina nas junções nervosas (ou sinapses), o que impede a interrupção da propagação do impulso elétrico. Consequientemente, o sistema nervoso central continuará sendo estimulado, desencadeando o processo de paralisia que pode culminar com a morte do inseto.

\section{Carbamatos}

Os carbamatos são inseticidas derivados do ácido carbâmico e sua comercialização teve início por volta dos anos 1960. Entre os mais utilizados, está o carbaril. Assim como os organofosforados, os carbamatos têm ação letal rápida sobre os insetos, apesar de um curto poder residual. São sistêmicos para as plantas, por serem relativamente solúveis em água. Como os organofosforados, também inibem a Acetilcolinesterase, embora, nesse caso, a reação envolvida seja a carbamilação. Apesar de atuarem de forma muito similar nos sistemas biológicos, apresentam duas diferenças principais em relação aos organofosforados. Primeiramente, alguns carbamatos são potentes inibidores da Aliesterase (uma Esterase alifática, cuja função exata é desconhecida) e apresentam seletividade pronunciada contra as AChE de certas espécies. A segunda diferença é que a inibição da AChE pelos carbamatos é reversível. ${ }^{43}$

\section{Piretróides}

Os piretróides sintéticos, atualmente bastante estáveis, são produzidos em laboratório, a partir de uma substância natural, o piretro, extraído de crisântemos. São biodegradáveis, não cumulativos e raramente provocam intoxicações agudas em aves e mamíferos, embora possam causar hipersensibilização e irritação das mucosas nesses animais. Para os animais aquáticos, entretanto, são extremamente tóxicos. Os piretróides contam, ainda, com as vantagens de serem muito ativos (atuam em pequenas doses) e desalojantes. Sua única desvantagem consiste no custo elevado. ${ }^{42}$

Os piretróides apresentam uma evolução interessante, dividida em quatro gerações. A primeira continha um só produto, aletrina, lançado no mercado em 1949, cuja síntese era muito complexa e envolvia 22 reações químicas até o produto final. A segunda geração incluía tetrametrina (1965), resmetrina (1967), bioresmetrina (1967), bioaletrina (1969) e phonotrina (1973). A terceira geração incluía fenvalerato e permetrina, surgidos em 1972-1973, que se tornaram os primeiros piretróides com uso agrícola, em função de sua alta atividade inseticida $\mathrm{e}$ fotoestabilidade. Na quarta e atual geração, altamente efetiva em doses baixas, incluem-se bifentrina, lambda-cialotrina, cipermetrina, ciflutrina, deltametrina, esfenvalerato, fenpropatrina, flucitrinato, fluvalinato, praletrina, taufluvalinato, teflutrina, tralometrina e zeta-cipermetrina, todos estes inseticidas fotoestáveis. ${ }^{43}$

Os piretróides apresentam modo de ação similar ao do DDT. Atuam, aparentemente, mantendo abertos os canais de sódio das membranas dos neurônios. Há dois tipos de piretróides: aqueles que, entre outras respostas fisiológicas, têm um coeficiente de temperatura negativo, assemelhando-se ao DDT (tipo 1); e os que apresentam coeficiente de temperatura positivo (tipo 2), ou seja, a mortalidade dos insetos a eles expostos varia diretamente com o aumento de temperatura. Os piretróides afetam o sistema nervoso periférico e central do inseto: estimulam as células nervosas a produzir descargas repetitivas e, eventualmente, causam paralisia. 0 efeito estimulante dos piretróides é muito mais pronunciado que o do DDT. ${ }^{43}$

\section{Resistência a inseticidas}

Os inseticidas têm sido bastante usados, tanto na agricultura e agropecuária quanto na área da Saúde Pública. Seu uso continuado tem provocado o aparecimento de populações resistentes e ocasionado problemas para o controle de vetores. Resistência tem sido detectada para todas as classes de inseticidas, afetando, direta e profundamente, a re-emergência das doenças transmitidas por vetores, ${ }^{54}$ pois, apesar dos importantes avanços alcançados no desenvolvimento de métodos alternativos, os inseticidas químicos continuam sendo uma importante ferramenta dos programas integrados de controle..$^{34}$ Nesse contexto, 0 monitoramento e o manejo da resistência, assim como o uso de substâncias com modos de ação diferentes dos inseticidas químicos convencionais, são elementos de suma importância em qualquer programa de controle de vetores. ${ }^{55}$

A resistência é definida pela OMS como a habilidade de uma população de insetos tolerar uma dose de inseticida que, em condições normais, causaria sua morte. A resistência - dita fisiológica - é uma 
característica genética, como, por exemplo, a cor dos olhos. Desse modo, populações de insetos, ácaros e outros artrópodes podem, naturalmente, apresentar uma proporção de indivíduos que tenham alelos que lhes confiram resistência a um determinado produto químico. Cepas resistentes podem surgir como resultado do uso persistente de pesticidas que matam indivíduos com alelos suscetíveis e não matam aqueles que possuam alelos resistentes.

A resistência a inseticidas pode ser pensada como um processo de evolução acelerada de uma população que responde a uma intensa pressão seletiva, com a conseqüente sobrevivência dos indivíduos que possuem alelos que conferem resistência. A resistência é pré-adaptativa, resultado de mutações fortuitas. Assim, um pequeno número de indivíduos possui características que permitem sua sobrevivência sob doses de inseticidas normalmente letais. 0 próprio inseticida não produz uma mudança genética; seu uso continuado, entretanto, pode selecionar indivíduos resistentes.

Apesar dos vários estudos documentados sobre a resistência, o número de mecanismos envolvidos é bastante pequeno e inclui diminuição da taxa de penetração pela cutícula, detoxificação metabólica aumentada e diminuição da sensibilidade do sítioalvo. Todos esses mecanismos são inespecíficos e, geralmente, conferem resistência cruzada a outro inseticida estruturalmente relacionado. ${ }^{55}$

\section{Redução na taxa}

\section{de penetração do inseticida}

Este mecanismo de resistência, associado a vários insetos, foi estudado principalmente na mosca doméstica. Quando comparado com outros mecanismos, é considerado de importância secundária por conferir, tão-somente, um baixo nível de resistência. ${ }^{56}$ Não obstante, em combinação com outros mecanismos, pode resultar em um incremento da resistência. A base bioquímica da redução da taxa de penetração de um inseticida não está clara, embora tenha sido proposto que a composição protéica do integumento tenha papel relevante.

\section{Resistência metabólica}

Há muitos casos descritos de resistência decorrentes do aumento da capacidade de metabolização de inseticidas, que leva à formação de produtos menos tóxicos. 0 incremento do metabolismo pode ser o resultado de alteração, seja da enzima existente, tornando-a mais eficaz na degradação dos inseticidas, seja dos mecanismos reguladores, que aumentam a produção de moléculas de enzimas já disponíveis em insetos suscetíveis, embora em quantidades muito pequenas. $^{54,55}$

Geralmente, as enzimas envolvidas em metabolismo de xenobióticos podem ser divididas em enzimas de Fase 1 e enzimas de Fase 2. As enzimas de Fase 1 reconhecem e atuam diretamente sobre o composto exógeno, introduzindo um grupo polar reativo na molécula, o que dá origem a substrato para as enzimas de Fase 2. A detoxificação que contribui para a resistência a inseticidas é realizada por enzimas de Fase 1, como as Monooxigenases e Esterases, ou de Fase 2, caso das glutationa S-transferases.

\section{Monooxigenases}

0 metabolismo oxidativo aumentado foi implicado como o principal mecanismo de resistência para todas as classes de inseticidas, com exceção dos ciclodienos, e é um dos mecanismos mais comuns de resistência. As enzimas associadas com o metabolismo oxidativo aumentado são as Monooxigenases dependentes de citocromo $\mathrm{P} 450,{ }^{57,58}$ especialmente concentradas no intestino, no corpo gorduroso e nos túbulos de Malpighi dos insetos.

Evidência inicial do envolvimento de metabolismo oxidativo com a resistência pode ser obtida com a adição, em bioensaios com inseticidas, de inibidores de Oxidases, como o butóxido de piperonil (que atua, aqui, como sinergista). Nesses casos, avalia-se a capacidade do sinergista de reduzir a magnitude da resistência. Embora essa técnica não seja conclusiva, é valiosa como uma primeira indicação de que 0 aumento da atividade de Monooxigenases está contribuindo para a resistência. ${ }^{57,58}$

\section{Esterases}

Vários inseticidas que contêm o grupamento éster na sua estrutura química (organofosforados, carbamatos e piretróides) são suscetíveis à reação de hidrólise. As enzimas que catalisam essas reações são coletivamente chamadas de Hidrolases, ou Esterases. São também chamadas Carboxilesterases quando hidrolisam compostos que apresentam ésteres carboxílicos em sua estrutura, como a maioria dos organofosforados, que 
são ésteres de ácido fosfórico. ${ }^{54,59} \mathrm{O}$ envolvimento das Esterases com a resistência pode ser verificado com a adição de inibidores em ensaios com os inseticidas, como o S,S,S-tributil fosforotioato (DEF) ${ }^{54,59}$

\section{Glutationa S-transferases (GST)}

São enzimas multifuncionais capazes de detoxificar um grande número de xenobióticos. Essas enzimas catalisam a conjugação do grupo hidrofílico $\mathrm{SH}$ da glutationa reduzida (GSH) ao centro eletrofílico de compostos lipofílicos. ${ }^{60}$ Várias formas dessas enzimas são conhecidas em mosquitos, mosca doméstica, Drosophila e outros insetos. ${ }^{61-63}$

\section{Alteração do sítio-alvo}

Todos os inseticidas químicos descritos até aqui atuam no sistema nervoso central, em diferentes sítiosalvo. Resistência de uma população de insetos pode ser decorrente de alteração desses sítios, de forma a impedir - ou dificultar - a ligação com o inseticida.

\section{Acetilcolinesterase (AChE)}

É o sítio-alvo de organofosforados e carbamatos. ${ }^{60}$ Essa enzima é a responsável pela degradação de acetilcolina, neurotransmissor que, quando presente na fenda sináptica, promove a propagação do impulso nervoso, uma vez que provoca a abertura de canais de sódio na célula pós-sináptica. Em situação normal, após a cessação do estímulo, a acetilcolina é removida por recaptação ou por degradação enzimática, sendo a acetilcolinesterase a enzima responsável. Organofosforados e carbamatos atuam inibindo a AChE e, em consequiência, a acetilcolina permanece na fenda sináptica e 0 impulso não cessa, levando 0 inseto à morte. Nestes casos, a resistência está relacionada com afinidade reduzida da AChE pelo inseticida, o que permite a interrupção normal - ou quase - do estímulo nervoso..$^{55,60,64}$

\section{Canais de sódio}

São os principais sítios-alvo dos piretróides e de alguns organoclorados [como os difenil-alifáticos (DDT) e o hexaclorociclohexano (BHC)]. A ligação desses inseticidas mantém os canais de sódio na conformação aberta e, conseqüentemente, há propagação contínua do impulso nervoso, podendo levar o inseto à morte. A resistência é resultante de sensibilidade reduzida do canal de sódio a esses compostos. ${ }^{43,60,65}$
Mais conhecido como mecanismo knockdown (ou kdr), esse tipo de resistência a DDT e piretróides foi registrado para várias espécies ${ }^{66}$ mas é melhor caracterizado em moscas domésticas, para as quais diversas variantes de kdr são descritas, inclusive 0 fator super-kdr. ${ }^{67}$

\section{0 monitoramento e manejo da resistência e o uso de substâncias com modos de ação distintos dos inseticidas químicos convencionais são de suma importância para qualquer programa de controle de vetores.}

Por causa da resistência cruzada entre DDT e piretróides, ensaios biológicos que identificam resistência a ambas as classes de inseticidas podem ser úteis como um indicador de resistência do tipo kdr.

\section{Receptores do ácido gama-aminobutírico (GABA)}

São o sítio-alvo dos ciclodienos e policloroterpenos (organoclorados). Pertencem a uma superfamília de receptores presentes nas junções sinápticas do sistema nervoso central e das sinapses neuromusculares de insetos. ${ }^{60}$ Os inseticidas atuam sobre os receptores de GABA, impedindo a entrada de íons cloro para 0 meio intracelular e, com isso, provocando a emissão de impulsos espontâneos que levam à contração muscular, convulsões, paralisia e morte. A resistência, ocasionada por insensibilidade do receptor de GABA aos inseticidas, já foi associada com mutação de único par de bases do receptor, ocasionando substituição de um aminoácido (alanina por serina).$^{60}$

\section{Inseticidas alternativos}

Além dos inseticidas químicos propriamente ditos, outros produtos vêm sendo usados no controle de vetores. Eles pertencem, principalmente, aos grupos dos inseticidas biológicos e dos reguladores de crescimento.

Como exemplo de inseticidas biológicos, pode-se citar as bactérias patógenas, que têm sido usadas no controle de pragas agrícolas por quase cinco décadas. 
Somente por volta dos anos 1970, foram descobertas bactérias efetivas contra insetos de importância médica, principalmente mosquitos e simulídeos.

Em 1964, foi descrita uma cepa de Bacillus sphaericus (Bs) com efetividade contra mosquitos. ${ }^{68}$ Embora seu espectro de ação seja restrito a certos tipos de larvas de mosquito, sua eficácia em águas poluídas tornou-a particularmente útil contra espécies de Culex, vetores de filarioses e de encefalites viróticas. Durante a última década, tem aumentado o uso de Bs em programas de controle de mosquitos que se desenvolvem em águas poluídas, em áreas urbanas. ${ }^{69}$

Outra bactéria, o Bacillus thuringiensis israelensis (Bti) ${ }^{70}$ provou ser tão efetiva que, alguns anos depois de sua descoberta, tornou-se um dos principais componentes do Programa de Controle de Oncocercose da África Ocidental e, posteriormente, passou a ser usada como uma alternativa para inseticidas químicos sintéticos em muitos programas de controle de mosquitos. $^{71}$

Bti e Bs são bactérias entomopatogênicas cujos esporos apresentam cristais, que produzem prótoxinas. As larvas de culicídeos ingerem os cristais, que são dissolvidos no intestino alcalino do inseto. As proteases digestivas clivam as pró-toxinas presentes nos cristais e ativam seu componente inseticida. Os peptídeos tóxicos resultantes agem sobre o epitélio intestinal das formas imaturas do vetor, promovendo a diminuição do peristaltismo e, conseqüentemente, a interrupção da alimentação e a morte da larva. ${ }^{72,73}$ Bti é um dos larvicidas recomendados pela OMS para uso em água potável com objetivo de controlar larvas do Ae. aegypti, ${ }^{47}$ sendo, portanto, um dos substitutos possíveis para o temephos.

Produtos à base de Bti têm sido usados em programas de controle de mosquitos e simulídeos por mais de 20 anos. Apesar disso, até o momento, não houve registro de resistência, provavelmente porque várias proteínas com atividade inseticida estão presentes nesses cristais. No caso de Bs, cujo ingrediente ativo principal é uma única toxina, a resistência já se desenvolveu em algumas populações na Índia, no Brasil e na França. Assim, o potencial para o desenvolvimento de resistência com o uso mais difundido de Bs é alto. Recentes estudos mostraram, no entanto, que essa resistência pode ser alvo de manejo, mediante esquema de rotação de produtos à base de Bs e de produtos à base de Bti ou outros larvicidas. ${ }^{69,71}$
Os reguladores de crescimento (ou IGR, sigla derivada de Insect Growth Regulator), que atuam no desenvolvimento e na reprodução dos insetos, também são considerados inseticidas alternativos. Os IGR mais utilizados no controle de mosquitos pertencem ao grupo das benzoil-fenil-uréias (BPU, inibidores de síntese de quitina) ou são compostos quimicamente relacionados ao hormônio juvenil natural de insetos, designados como análogos de hormônio juvenil $(\mathrm{AHJ}) .^{74} \mathrm{Em}$ geral, os IGR apresentam altos níveis de atividade e eficácia no controle de várias espécies de insetos, em diferentes babitat. ${ }^{75}$

As BPU inibem a síntese de quitina nos insetos, ${ }^{76}$ resultando em interferência com a formação de cutícula a cada vez que 0 inseto inicia a muda. ${ }^{77}$ Isso ocorre porque a cutícula apresenta quitina em sua composição. Entre os inibidores da síntese de quitina mais utilizados, encontram-se 0 diflubenzuron e 0 triflumuron, ambos recomendados pela OMS como larvicidas. ${ }^{47} \mathrm{Um}$ inibidor da síntese de quitina foi recentemente aprovado pela OMS para uso em água potável. ${ }^{78}$

Os AHJ interferem com o sistema endócrino dos insetos. Vale mencionar que os processos de muda, metamorfose, desenvolvimento ovariano e aquisição da capacidade reprodutiva nos insetos são basicamente controlados por um sistema compreendido por três hormônios: o hormônio protoracicotrópico (PTTH), produzido pela corpora cardiaca; a ecdisona, ou 'hormônio da muda', sintetizada pelas glândulas protorácicas nos insetos imaturos (e, nos mosquitos adultos, pelos ovários); e o hormônio juvenil (HJ), sesquiterpenóide produzido na corpora allata. ${ }^{79,80}$ o papel dos hormônios na fisiologia da muda foi inicialmente descrito por Wigglesworth, na década de $19300^{81-84}$

Nos estágios imaturos, a ecdisona, produzida em resposta ao PTTH, atua na indução da muda, enquanto o HJ confere o caráter juvenil aos estádios subseqüentes. No último estágio larvar, quando apenas a ecdisona está presente, ocorre a metamorfose para o estágio adulto (na ausência de HJ). No adulto, tanto a ecdisona quanto o $\mathrm{HJ}$ têm papel na produção dos ovos. ${ }^{80}$

Os AHJ, ou terpenóides, atuam sobre o desenvolvimento dos insetos, inibindo a emergência dos adultos. ${ }^{77}$ Entre os produtos pertencentes a essa classe, a OMS recomenda, para controle de larvas de mosquitos, methoprene e pyriproxifen. ${ }^{47}$ 
Methoprene [isopropil (2E, 4E)-11-metoxi-3,7,11trimetil-2,4-dodecadienoato] foi primeiramente registrado em 1975 e é um dos mais antigos análogos de hormônio juvenil desenvolvidos, sendo um dos produtos recomendados pela OMS para uso em água potável, com propósito de controle do Ae. aegypti. ${ }^{47}$

Vários estudos demonstraram que a maioria das espécies não-alvo não era afetada pelos $\mathrm{AHJ},{ }^{85}$ embora tenha sido detectado um decréscimo na densidade de populações de Chironomidae e de Psychodidae após aplicação de methoprene. ${ }^{85}$

Embora os IGR possam ser um importante elemento no manejo da resistência a inseticidas, uma vez que atuam de maneira diferente dos inseticidas tradicionais, já existem registros de resistência a esses compostos. A resistência aos IGR está relacionada às

\section{Referências bibliográficas}

1. Bancroft TL. On the etiology of dengue fever. Australasian Medical Gazette.1906;25:17-18.

2. Rodhain F, Rosen L. Mosquito vectors and dengue virus-vector relationships. In: Gubler DJ, Kuno G. Dengue and dengue hemorragic fever. New York: $\mathrm{CAB}$ International; 1997.

3. World Health Organization. Dengue [monography on the Internet] Geneve: WHO; 2002 [capturado 2002 set. 18]. Disponível em: http://www.who.int/ctd/ dengue/burdens.htm

4. Jumali Sunarto, Gubler DJ, Nalim S, Eram S, Sulianti Saroso J. Epidemic dengue hemorrhagic fever in rural Indonésia. III. Entomological studies. American Journal of Tropical Medicine and Hygiene1979;28(4):717-724.

5. Eamchan P, Nisalak A, Foy HM, Chareonsook OA. Epidemiology and control of dengue virus infections in Thai villages in 1987. American Journal of Tropical Medicine and Hygiene 1989;41(1):95-101.

6. Chareonsook DC, Yap HH. Chemical methods for the control of vector and pests of public health importance. Geneve: WHO; 1977. WHO/CTD/ WHOPES/97.2.

7. Serufo SC, Oca HM, Tavares VA, Souza AM, Rosa RV, Jamal MC, Lemos JR, Oliveira MA, Nogueira RMR, Schatzmayr HG. Isolation of dengue virus type 1 from
Monooxigenases $^{54,89}$ e foi detectada, principalmente, na mosca doméstica. ${ }^{90,91}$

A variedade de inseticidas disponíveis para o controle de vetores de importância médica é reduzida. Aliados a isso, a resistência a produtos convencionais e o potencial desenvolvimento de resistência a reguladores do desenvolvimento de insetos indicam a necessidade de um controle racional de vetores que considere os diferentes componentes do controle integrado.

Nesse contexto, a utilização de inseticidas deve ser vista como uma ferramenta complementar à vigilância e às ações de redução de criadouros. Ademais, o levantamento de dados relativos à resistência das populações de vetores e de seus mecanismos é importante para que a aplicação de inseticidas no campo tenha a melhor relação custo-benefício.

larvae of Aedes albopictus in Campos Altos city, state of Minas Gerais, Brazil. Memórias do Instituto Oswaldo Cruz 1993;88(3):503-504.

8. Ibañez-Bernal S, Briseno B, Mutebi JP, Argot E, Rodriguez G, Martinez-Campos C, Paz R, de la FuenteSan Roman P, Tapia-Conyer R, Flisser A. First record in America of Aedes albopictus naturally infected with dengue virus during the 1995 outbreak at Reynosa, Mexico. Medical and Veterinary Entomology 1997;11(4):305-309.

9. Gomes AC. Medidas dos níveis de infestação urbana para Aedes (Stegomyia) aegypti e Aedes (Stegomyia) albopictus. Informe Epidemiológico do SUS 1998;7(3):49-57.

10. Nelson MJ. Aedes aegypti: biologia y ecologia. Washington, DC, Organización Panamericana de la Salud; 1986.

11. Christophers SR. Aedes aegypti (L.), the Yellow Fever Mosquito. Its life history, bionomics and structure. London: Cambridge University Press; 1960.

12. Organización Panamericana de la Salud. Dengue y dengue hemorrágico en las Américas: guías para su prevención y control. Washington, DC: OPS; 1995.

13. Rodriguez Exposito C, Carlos J Finlay. Obras completas. Habana, Cuba: Academia de Ciencias de Cuba; 1971. 
14. Bisset JA. Uso correcto de insecticidas: control de la resistencia. Revista Cubana de Medicina Tropical 2002;54(3):202-219.

15. Martinez EM. Dengue hemorrágico en niños. Habana, Cuba: Ed. José Marti; 1990.

16. Halstead SB. Etiologies of the experimental dengues of Siler and Simmons. American Journal of Tropical Medicine \& Hygiene 1974;23(5):974-982.

17. Centers for Disease Control. Control of Dengue. Vector Topics 1979;2:1-39.

18. Franco 0. Reinfestação do Pará por Aedes aegypti. Revista Brasileira de Malariologia e Doenças Tropicais 1969;21(4):729-731.

19. Pan-American Health Organizacion. Number of Reported Cases of Dengue \& Dengue Hemorrhagic Fever (DHF), Region of the Americas (by country and subregion) 2004 [monografia na Internet]. Washington, DC: PAHO; 2004 [cited 2004 Feb 3]. Disponível em: http://www.paho.org/english/ad/dpc/ cd/dengue-cases-2003.htm.

20. Secretaria de Vigilância em Saúde. Departamento de Análise de Situação de Saúde. Dados e indicadores selecionados. Brasília: Ministério da Saúde; 2003.

21. Lourenço-de-Oliveira R, Vazeille M, de Filippis AMB, Failloux AB. Aedes aegypti in Brazil: genetically differentiated populations with high susceptibility to dengue and yellow fever viruses. American Journal of Tropical Medicine \& Hygiene 2004;98:43-54.

22. Lounibos LP. Invasions by insect vectors of human disease. Annual Review of Entomology 2002;47:233266.

23. Forattini OP. Identificação de Aedes (Stegomya) albopictus (Skuse) no Brasil. Revista de Saúde Pública 1986;20:5.

24. Fundação Nacional de Saúde. Dengue: instruções para pessoal de combate ao vetor. Manual de normas técnicas. Brasília: Funasa; 2001.

25. Santos RC. Updating of the distribution of Aedes albopictus in Brazil (1997-2002). Revista de Saúde Pública 2003;37(5):671-673.

26. Centers for Disease Control. Information on Aedes albopictus [monografia na Internet]. Atlanta: CDC; 2003 [cited 2000 Dic 12]. Disponível em: http:// www.cdc.gov/information on Aedes albopictus.html
27. Miller JG, Ballinger ME. Aedes albopictus mosquitoes introduced into Brazil: Vector competence for yellow fever and dengue viruses. Transactions of the Royal Society of Tropical Medicine and Hygiene 1988;82:476-477.

28. Lourenço-de-Oliveira R, Vazeille M, de Filippis $\mathrm{AMB}$, Failloux AB. Large genetic differentiation and low variation in vector competence for dengue and yellow fever viruses of Aedes albopictus from Brazil, the United States, and the Cayman Islands. American Journal of Tropical Medicine and Hygiene 2003;69(1):105-114.

29. Rozendaal JA. Vector control methods for use by individuals and comnunities. Geneve: World Health Organization; 1997.

30. Braga IA, Galardo AKR, Machado Filho MR, Zimmerman R, Braga IL. Controle seletivo de vetores da Malária: guia para o nível municipal. Brasília: Ministério da Saúde; 1999.

31. World Health Organization. Vector Control for Malaria and other Mosquito-Borne Diseases Report of a WHO Study Group. Geneva: WHO; 1995. WHO TRS n ${ }^{\circ} 857$.

32. Organização Pan-Americana da Saúde. Implementação do controle seletivo de vetores da Malária na Região Amazônica. Brasília: OPAS; 1997.

33. Organización Panamericana de la Salud. Control selectivo de vectores de malaria: guía para el nivel local de los sistemas de salud. Washington, DC: OPS; 1999.

34. Rose RI. Pesticides and public health: integrated methods of mosquito management. Emerging Infectious Diseases 2001;7(1):17-23.

35. Hoy JB. Experimental mass-rearing of the mosquitofish, Gambusia affinis. Journal of American Mosquito Control Association 1985;1(3):295-298.

36. Mulla MS, Federici BA, Darwazeh HA, Ede L. Field evaluation of the microbial insecticide Bacillus thuringiensis serotype H-14 against floodwater mosquitoes. Applied Environmental Microbiology 1982;43(6):1288-1293.

37. Goldberg LJ, Margalit J. A bacterial spore demonstrating rapid larvicidal activity against Anopheles sergei unguilata, Culex univittata, Aedes aegypti and Culex pipiens. Mosquito News 1977;37:355-358. 
38. Mulligan III, FS, Schaefer CH, Wilder WH. Efficacy and persistence of Bacillus sphaericus and $B$. thuringiensis $\mathrm{H} .14$ against mosquitoes under laboratory and field conditions. Journal of Econonic Entomology 1980;73:684-688.

39. Scholte EJ, Nijiru BN, Smallegange RC, Takken W, Knols BG. Infection of malaria (Anopheles gambiae s.s.) and filariasis (Culex quinquefasciatus) vectors with the entomopathogenic fungus Metarbizium anisopliae. Malaria Journal 2003;2(1):1-8.

40. Mellon RB, Georghiou GP. Rotational use of insecticides in mosquito control programs. Proceedings and papers of the fifty-second annual Conference of the California and Vector Control Association 1984;65-67.

41. Rathburn Jr CB. Insecticide formulations - types and uses: a review. Journal of American Mosquito Control Association 1985;1(1):80-84.

42. Palchick S. Chemical Control of Vectors In: The Biology of Disease Vectors. Colorado: University Press of Colorado; 1996.

43. Ware GW. An introduction to insecticides [monografia na Internet]. 3rd ed. University of Minnesota; 2000 [cited 2003 Nov 03]. Disponível em: http://ipmworld. umn.edu/chapters/ware.htm

44. Chen A, Rogan WJ. Nonmalarial infant deaths and DDT use for malaria control. Emerging Infectious Diseases 2003;9(8):960-964.

45. Ferrer A. Pesticide poisoning. Anales del Sistema Sanitario de Navarra 2003;26(1):155-171.

46. Waliszewski SM, Gomez-Arroyo S, Infanzon RM, Villalobos-Pietrini R, Hart MM. Comparison of organochlorine pesticide levels between abdominal and breast adipose tissue. Bulletin of Environmental Contamination and Toxicology 2003;71(1):156-162.

47. Chavasse DC, Yap HH. Chemical methods for the control of vectors and pests of public health importance. Geneve: WHO; 1997. WHO/CTD/ WHOPES/97.2.

48. Roberts DR, Laughlin LL, Hsheih P, Legters LJ. DDT, global strategies, and a malaria control crisis in South America. Emerging Infectious Diseases 1997;3(3):295-302.

49. Bouwman H, Cooppan RM, Reinecke AJ, Becker PJ. Levels of DDT and metabolites in breast milk from Kwa-Zulu mothers after DDT application for malaria control. Bulletin of the World Health Organization 1990;68:761-768.

50. Garabrant DH, Held J, Langholz B, Peters JM, Mack TM. DDT and related compounds and risk of pancreatic cancer. Journal of the National Cancer Institute 1992;84:764-771.

51. Wolff MS, Toniolo PG, Lee EW, Rivera M, Dubin N. Blood levels of organochlorine residues and risk of breast cancer. Journal of the National Cancer Institute 1993;85(8):648-652.

52. Roberts DR, Manguin S, Mouchet J. DDT house spraying and re-emerging malaria. Lancet 2000; 356:330-332.

53. Crinnion WJ. Environmental Medicine, Part 4: Pesticides - Biologically Persistent and Ubiquitous Toxins. Alternative Medicine Review 2000;5(5):432447.

54. Brogdon WG, McAllister JC. Insecticide resistance and vector control. Emerging Infectious Diseases 1998;4(4):605-613.

55. Ferrari JA. Insecticide resistance In: The Biology of Disease Vectors. Colorado: University Press of Colorado; 1996.

56. Oppenoorth FJ. Biochemical and genetic in insecticide resistance. In: Kerkut GA, Gilbert LI, editors. Comprehensive Insect Physiology Biochemistry and Pharmacology 1985;12:731-773.

57. Bergé J, Feyerensen R, Amichot M. Cytochrome P450 monoxygenases and insecticide resistance in insects. Philosophical Transactions Royal Society London Series B: Biological Sciences 1998;353:1701-1705.

58. Scott JG. Cytochromes P450 and insecticide resistance. Insect Biochemistry and Molecular Biology 1999;29(9):757-777.

59. Hemingway J, Karunaratne SH. Mosquito carboxylesterases: a review of the molecular biology and biochemistry of a major insecticide resistance mechanism. Medical and Veterinary Entomology 1998;12(1):1-12.

60. Hemingway J, Ranson H. Insecticide resistance in insect vectors of human disease. Annual Review Entomology 2000;45:371-391.

61. Clark AG, Shamaan NA, Dauterman WC, Hayaoka T. Characterization of multiple glutathione transferases from the house fly, Musca domestica (L.). Pesticide Biochemistry and Physiology 1984;22:51-59. 
62. Clark AG, Dick GL, Martindale SM, Smith JN. Glutathione S-transferases from the New Zealand gras grub, Costelytra zealandica. Insect Biochemistry 1985; 15:35-44.

63. Toung YP, Hsieh TS, Tu CP. Drosophila glutathione S-transferase 1-1 shares a region of sequence homology with the maize glutathione S-transferase III. Proceedings of the National Academy of Sciences USA 1990;87(1):31-35.

64. Ffrench-Constant RH, Pittendrigh B, Vaughan A, Anthony N. Why there so few resistance-associated mutation target genes? Philosophical Transactions of the Royal Society London 1998;353:1685-1693.

65. Bloomquist JR. Toxicology, mode of action and target site-mediated resistance to insecticides acting on chloride channels. Comparative Biochemistry and Physiology 1993;106(2):301-314.

66. Vais H, Williamson MS, Goodson SJ, Devonshire AL, Warmke JW, Usherwood PN, Cohen CJ. Activation of Drosophila sodium channels promotes modification by deltamethrin. Reductions in affinity caused by knock-down resistance mutations. Journal of General Physiology 2000;115(3):305-318.

67. Farnham AW, Murray AWA, Sawicki RM, Denholm I, White JC. Characterization of the structure activity relationship of $\mathrm{kdr}$ and two variants of super-kdr to pyrethroids in the housefly (Musca domestica). Pesticide Science 1987;19:209-220.

68. Kellen WR, Meyers CM. Bacillus sphaericus Neide as a pathogen of mosquitoes. Journal of Invertebrate Pathology 1964;7:442-448.

69. World Health Organization. Guideline specifications for bacterial larvicides. Geneve: WHO; 1999.

70. de Barjac. A new variety of Bacillus thuringiensis very toxic to mosquitoes: B. thuringiensis var. israelensis serotype 14. Comptes Rendus Hebdomadaires des Séances de l'Académie des Sciences Série D 1978;286(10):797-800.

71. World Health Organization. Environmental Health Criteria 217. Bacillus thuringiensis. Geneve: WHO; 1999.

72. Gill SS, Cowles EA, Pietrantonio PV. The mode of action of Bacillus thuringiensis endotoxins. Annual Review of Entomology 1992;37:615-636.

73. Federici BA. The future of microbial insecticides as vector control agents. Journal of the American Mosquito Control Association 1995;11(2):260-268.
74. Slama K, Romanuk M, Sorm F. Insect Hormones and Bioanalogues. New York: Springer Verlag; 1974.

75. Mulla MS, Darwazeh HA, Schreiber ET. Impact of new insect growth regulators and their formulations on mosquito larval development in impoundment and floodwater habitats. Journal of the American Mosquito Control Association 1989;5(1):15-20.

76. Post LC, Mulder R. Insecticidal properties and mode of action of 1-(2,6-dihagenzoyl)-3-phenylureas. Los Angeles, CA: American Chemical Society National Meeting; 1974.

77. Mian LS, Mulla MS. Biological and environmental dynamics of insect growth regulators (IGRs) as used against Diptera of public health importance. Residue Review 1982;84:27-112.

78. Novaluron 2004. WHO specifications and evaluations for public health pesticides [monografia na Internet]. Geneve: WHO [citado 2005 Jan 12]. Disponível em: http://www.who.int/whopes/quality/ newspecif/en/

79. Clements AN. The endocrine system and hormones In: The Biology of Mosquitoes: vol. 1 - Development, nutrition and reproduction. London: Chapman \& Hall; 1992.

80. Valle D. Vitellogenesis in insects and other groups - a Review. Memórias do Instituto Oswaldo Cruz 1993;88(1):1-26.

81. Wigglesworth VB. The physiology of ecdysis in Rhodnius prolixus (Hemiptera). II. Factors controlling moulting and metamorphosis. Quarterly Journal of Microscopical Science 1934;77:121-222.

82. Wigglesworth VB. Factors controlling moulting and metamorphosis in an insect. Nature 1934;135:725-726.

83. Wigglesworth VB. Function of the corpus allatum in insects. Nature 1935;136:338.

84. Wigglesworth VB. The function of the corpus allatum in the growth and reproduction of Rhodnius prolixus (Hemiptera). Quarterly Journal of Microscopical Science 1936;79:91-121.

85. Miura T, Takahashi RM. Insect development inhibitors. Effects of candidate mosquito control agents on nontarget aquatic organisms. Environmental Entomology 1974;3:631-636.

86. Norland RL, Mulla MS. Impact of Altosid on selected members of an aquatic ecosystem. Environmental Entomology 1975;4:145-152. 
87. Creekmur GD, Russsel MP, Hazelrigg JE. Field evaluation of the effects of slow release wettable powder formulation of Altosid on nontarget organisms. Proceedings and Papers California Mosquito and Vector Control Association 1981; 49:95-97.

88. Chu KH, Wong CK, Chiu KC. Effects on the insect growth regulator (S)-methoprene on survival and reproduction of the freshwatwer cladoceran Moina macrocopa. Environmental Pollution 1997;96: 173-178.

89. Kotze AC, Sales N, Barchia IM. Diflubenzuron tolerance associated with monooxygenase activity in field strain larvae of the Australian sheep blowfly (Diptera: Calliphoridae). Journal of Economic Entomology 1997;90:15-20.
90. Cerf DC, Georghiou GP. Cross resistance to juvenile hormone analogues in insecticide-resistant strains of Musca domestica L. Pesticide Science 1974;5: 759-767.

91. Zhang L, Harada K, Shono T. Cross resistance to insect growth regulators in pyriproxyfen-resistant housefly. Applied Entomology and Zoology 1998; 33:195-197.

Recebido em 20/11/2005

Aprovado em 04/06/2007 